\title{
Etnomatemática e infâncias brincantes
}

\section{Érica Helena de Proença Alexandrini}

\section{Resumo}

Problematizo neste texto a condição do ser criança no espaço e tempo da Educação Infantil, na busca de compreensão do desenvolvimento integral nas infâncias brincantes, considerando a cultura no processo educativo, em acordo com os pressupostos da Etnomatemática, que está relacionado a realidade mais próxima da criança, na qual ela conhece, interage e possibilita o apreender de novos conceitos. Abordo, brevemente, a produção das culturas infantis entre crianças pequenas e descrevo duas experiências brincantes com crianças da Educação Infantil no município de Campinas, do CEI “João Vialta”, no ano de 2014; uma fazendo massa de modelar com pó de café e outra confeccionando de brinquedos com materiais recicláveis, que possibilitaram interações entre a escola e a família e o apreender de saberes da cultura local. O brincar e o apreender na reutilização de materiais recicláveis podem contribuir para afastar as crianças do consumismo desenfreado de brinquedos industrializados, que focam o público infantil no intuito de vender cada vez mais seus produtos e acumular capital.

Palavras-chave: Educação Infantil, Etnomatemática, múltiplas linguagens. 


\section{Introdução}

Este estudo foi realizado no CEI "João Vialta", Campinas/SP, em que atuo como professora no agrupamento III-D com faixas etárias entre quatro e seis anos, onde problematizo as infâncias brincantes e seus aprendizados. Problematização que surgiu nas aulas do Curso "Etnomatemática e Prática Pedagógica: da Educação Infantil ao Ensino Fundamental” oferecido pela Secretaria Municipal de Educação de Campinas/SP, no ano de 2014, onde havia espaço para a socialização de algumas práticas pedagógicas realizadas com as crianças e famílias. A proposta desse curso foi experimentar, no cotidiano da sala de aula, uma prática norteada pela investigação de determinados assuntos com as crianças, na perspectiva da Etnomatemática e a produção de conhecimento sobre a nossa própria prática.

Considero a educação infantil como espaço de educação de crianças e de profissionais docentes e não docentes, mães, pais, familiares e membros da comunidade, reconhecendo e conhecendo as crianças e sua condição infantil, colocando teorias e práticas educativas em diálogo.

Nesse percurso, faço um breve panorama do que é ser criança, abordo as múltiplas linguagens e descrevo algumas atividades de Etnomatemática.

\section{O ser criança e o desenvolvimento integral}

A legislação brasileira define o que é ser criança e seus direitos; o que na prática nem sempre acontece devido a situações como exclusão social, exploração do trabalho infantil, exposição a rotinas desgastantes, que fazem parte dos valores e práticas do mundo adulto impostas à infância.

A condição infantil através das relações de idade e da produção das culturas infantis entre crianças pequenas, em contexto educativo, precisa ser pensada com cuidado, como mostra o estudo de Prado (2006) em uma pesquisa desenvolvida em um CIMEI (Centro Integrado Municipal de Educação Infantil), no município de Campinas, onde se avalia o cotidiano da instituição com a colaboração das professoras que tiveram as salas mudadas para os agrupamentos multietários. Uma das observações mostra que se faz necessário criar condições para que as crianças maiores e menores estabeleçam relações entre si, o que exige atenção especial na construção de propostas pedagógicas. Um processo pedagógico que considere as diferenças como etária, de gênero, de etnia e classe social exige planejamento, organização, estudo, observação, registro, especialmente formação profissional que amplie o olhar, a escuta e disposição para conhecer e apreender com as crianças pequenas.

No município de Campinas foi implementada uma resolução para agrupamentos multietários para a Educação Infantil, a SME ${ }^{0}$ 23/2002, publicada em Diário Oficial do dia 13/11/2002, que propõe a divisão das crianças a serem matriculadas em turmas por idade aproximada: Agrupamento I - crianças de 03 meses a 01 ano e 11 meses; Agrupamento II crianças de 2 a 3 anos e 11 meses; Agrupamento III - crianças de 4 a 6 anos.

\footnotetext{
${ }^{2}$ Ministrado pela professora Maria Aparecida da Silva Damin.
} 
Os agrupamentos trouxeram novas oportunidades e boas ideias para aqueles que conseguiram se adaptar e se preparar. Porém, vieram munidos de críticas e defeitos pela imposição do sistema e pela falta de preparação, pois solucionou os problemas da parte política e criou problemas para aqueles que estão diretamente ligados à educação, como professores, monitores e outros profissionais da área. Conforme Abreu (2006, p. 30) “[...] a problemática frente a objetivos políticos, sociais, econômicos, luta pela cultura da infância, mudança de paradigma com relação à educação dos pequenos e concepção de infância".

Ainda com Abreu (2006), a finalidade dos agrupamentos é reunir as crianças em grupos, proporcionando formas diferentes de organizar o trabalho das crianças de zero a seis anos e novas possibilidades de trabalho ao professor. Os agrupamentos pressupõem atividades diversificadas, oferecendo uma gama de atividades e possibilidades para que as crianças façam escolhas a partir de seus desejos, interesses e amadurecimento. Processo pedagógico que gera cooperação na interação entre os maiores e menores, auxilia nas descobertas, nas brincadeiras, nos conflitos, nas negociações, na troca de experiências e vivências, gerando significado à aprendizagem e ao próprio desenvolvimento infantil.As Diretrizes Curriculares da Educação Básica para Educação Infantil (2013) afirmam:

[...] que a criança desde que nasce se constitui em sujeito sócio histórico e de direitos. Nesta perspectiva, vivencia diferentes experiências, estabelece relações entre crianças-crianças-adultos, aprende, brinca, explora, cria, imagina, fantasia, transgride, por meio de diversas linguagens: gestual, LIBRAS, verbal, plástica, dramática, musical. Pela fala e ações do adulto, os bebês e as crianças pequenas têm suas múltiplas linguagens interpretadas e significadas (p. 10).

A frase "vivencia diferentes experiências, estabelece relações entre crianças-criançasadultos" espelha o nosso cotidiano, de educadores do município de Campinas, em que envidamos esforços para garantir às crianças os tempos e espaços para serem crianças, ou seja, para vivenciarem as suas infâncias no período em que permanecem no espaço educativo.

A educação infantil, primeira etapa da educação básica visa o desenvolvimento integral da criança até seis anos de idade, em seus aspectos físico, psicológico, intelectual e social, complementando a ação da família e da comunidade (CAMARGO, 2013, p. 177).

“Desenvolvimento integral” precisa de ações da família em parceria com a escola, o que nem sempre acontece, pois, nossa função é complementar à ação da família e não temos como garantir que suas "infâncias" sejam vividas plenamente devido ao modo de vida adotado, dependendo de fatores como o social e econômico. As crianças mais carentes, muitas vezes, precisam ajudar no sustento da família, enquanto as crianças de famílias com maior poder aquisitivo, geralmente, são dotadas de uma 'agenda' repleta de atividades quase que diariamente, como aulas de inglês, ballet, natação, entre outras. Camargo (2013, p. 183), reconhece que a participação da família na escola é de fundamental importância para o desenvolvimento do trabalho pedagógico.

Os espaços na escola em que atuo são organizados de forma acolhedora, respeitosa e cooperativa facilitando a construção de relacionamentos e aprendizagens na realidade e cultura, 
como propõe a Etnomatemática. Nossas ações como educadores são flexíveis, consideramos a criança sujeito de direitos e potencialidades, procuramos garantir o tempo da infância brincante no sentido de valorizar o brincar e o equilíbrio entre os momentos de cuidar e educar. De acordo com Camargo (2013, p. 182), a construção de espaços criativos, coletivos e diferenciados, como casinha, cozinha, biblioteca, mercadinho, loja, brinquedos, fantasias e outros, se constituem em alternativa viável, capaz de diversificar as possibilidades do brincar. Quanto mais espaços forem criados e ativados, maiores chances as crianças têm para desenvolver a linguagem, o mundo do faz de conta, a socialização e a autonomia.

Além da organização, é nítida a riqueza de materiais e possibilidades de experiências que as crianças de diferentes idades podem vivenciar nos diferentes espaços. No dia dezenove de fevereiro de 2014, por exemplo, algumas crianças estavam no tapete da leitura lendo, brincando, conversando, de repente $\mathrm{N}$ ( 5 anos e 7 meses) passa por cima de B ( 5 anos e 1 mês) e B, indignado, exclama: "Despassa, senão vou ficar pequenininho". Kohan (2004), a partir do fragmento 52 de Heráclito sugere:

[...] que o próprio da criança não é ser apenas uma etapa, uma fase numerável ou quantificável da vida humana, mas um reinado marcado por outra relação intensiva - com o movimento. No reino infantil que é o tempo não há sucessão nem consecutividade, mas a intensidade da duração (p. 55).

São crianças de quatro, cinco, seis anos, vivendo sua infância intensamente no brincar, sem pensar no tempo cronológico, sedentas, aproveitam ao máximo os momentos de brincadeiras, vivências, experiências, oferecidas nos espaços educativos. Dinâmica que contribui no processo formativo das crianças ao estimular a criação, a invenção, a experimentação e o não conformismo como propõe Piaget.

Segundo Costa (2007, p. 47), um "pedagogo da infância” é um estudioso da cultura da infância e da cultura infantil, de suas manifestações na música, nas letras, na poesia, nas imagens, na pintura, enfim das múltiplas linguagens. A cultura como um:

[...] movimento da ancestralidade, e a ancestralidade é como um tecido produzido no tear africano: na trama do tear está o horizonte do espaço; na urdidura do tecido está a verticalidade do tempo.Entrelaçando os fios do tempo e do espaço cria-se o tecido do mundo que articula a trama e a urdidura da existência (OLIVEIRA, 2007 p. 245).

"Na urdidura da existência" ao "entrelaçar fios do tempo e do espaço" as crianças vivenciam múltiplas linguagens como propõe a escola italiana da cidade de Reggio Emília, inspirada no trabalho do educador LorisMalaguzzi (1997), que destaca as cem linguagens das crianças no cotidiano e na cultura infantil.

Mas, o que, de fato, significa trabalhar as "Cem Linguagens" das crianças? Significa que devemos educar ensinando e cuidando para que as crianças possam maravilhar-se com o impossível, experimentando, investigando, descobrindo, fantasiando e criando sua cultura infantil.... Ideias de brincadeiras, brinquedos... Experiências divertidas como a votação de um 
nome para o agrupamento III-D, em que diversos nomes foram surgindo e o mais votado foi "Turma do Jacaré".

A seguir descreverei algumas atividades da "Turma do Jacaré" com massa de modelar e confecção de brinquedos.

\section{Modelando e confeccionando brinquedos}

Ao pesquisar receitas de massa de modelar, encontramos uma receita confeccionada com pó de café, que interessou a todos. As receitas culinárias estão diretamente associadas às características culturais e sociais de um povo. Vejamos a receita da Massa de modelar com pó de café e uma foto da experimentação das crianças.

Misture uma xícara (de chá) de pó de café seco usado, uma xícara (de chá) de farinha de trigo e $1 / 2$ xícara (de chá) de sal numa bacia/travessa;

Acrescente cerca de $1 / 2$ xícara (de chá) de café frio (adicione apenas o suficiente para dar liga à massa, sem deixá-la grudenta);

A massa de café é uma massa de modelar cheirosa e que possui uma textura e cor interessantes. Guarde a massa de modelar em um saco plástico.

Na educação infantil, a massa de modelar permite aguçar os sentidos como o tato e o olfato. Esta brincadeira possibilita descobrir novas formas, cores, combinações, diferentes texturas e movimentos.

A modelagem também possibilita o desenvolvimento da coordenação motora fina, da criatividade e da observação. A criança ao brincar de massinha geralmente se comunica, pergunta, imagina, formula hipóteses, testa suas ideias, busca aperfeiçoar suas criações.

Figura 1: Confecção da massa de modelar

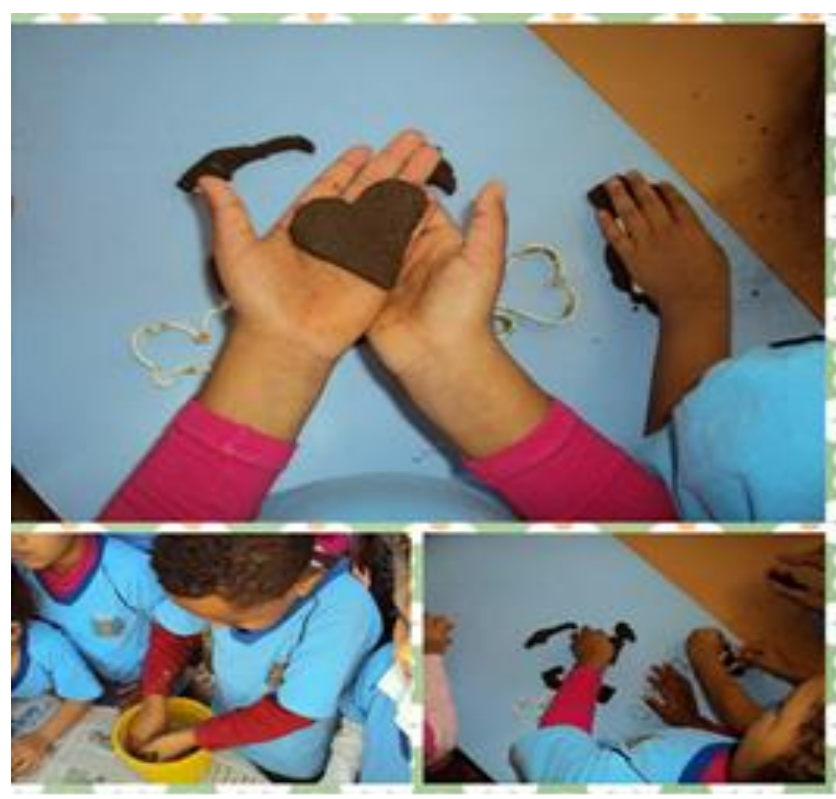

Fonte: Arquivo da autora

Na manipulação desta receita várias linguagens foram contempladas: oral, visual, escrita, matemática, plástica, como está disposto nas Diretrizes Curriculares: “ [...] não há uma linguagem que se sobreponha a outra, todas são importantes na Educação Infantil” (2013, p. 10). 
Em outras palavras, planejar atividades que envolvam receitas significa o convite a sentimentos de prazer, nas ações lúdicas das crianças.

Compartilhamos com as crianças e profissionais do CEI “João Vialta” a receita da massa de modelar com café e a gostosura do ser criança no processo educativo, ao mostrar um contexto significativo para a exploração da leitura, ainda que não convencionalmente.

Depois da experiência com a massa de modelar, Felipe solicitou a receita para que sua mãe pudesse fazer em casa: "Tia, você escreve no meu caderno como faz? ”Após o pedido de Felipe, outras crianças, meio que por "imitação", também solicitaram a receita para colar no "caderno de recados”.Para satisfazê-los, a receita foi digitada no computador e colada no caderno de cada criança. Recentemente uma mãe me contou que já reproduziu a receita em casa.

Ao manipular os ingredientes, as crianças foram tomando contato com conceitos matemáticos e de transformação de materiais ao observar que, para uma receita dar certo é necessário que utilizemos medidas/proporções, tais como: colheres (de sopa), xícaras (de chá). Caso errássemos nas quantidades a massa ficaria muito mole ou muito dura; o pó de café que iria para o lixo foi transformado em massa de modelar.

As crianças da Turma do Jacaré souberam seguir as instruções de forma correta, os resultados mostraram massinhas com boa textura e liga. A princípio, as crianças fizeram bolinhas exclamando: “Tia, estou fazendo brigadeiro!”. “Tia, vou fazer um salgadinho...” Aos poucos, as crianças foram vivenciando curiosidades, preferencias, sentidos, prazeres, brincadeiras, imaginação.

\section{Confeccionando brinquedos}

No início do ano letivo, durante as vivências e experiências em relação a Dengue, em parceria com as famílias, foi proposta a confecção de "mosquitos lúdicos" com a utilização de sucata, para valorizar o trabalho de pais e artesãos locais, estimulando a criatividade e a confecção de brinquedos com materiais reciclados, visando o cuidado com o meio ambiente, na direção da proposta da Secretaria de Educação Básica do MEC (2012):

Nos tempos atuais, a educação deve agregar as questões da diversidade, da sustentabilidade e da biodiversidade do país. Com suas florestas, matas, cerrados, rios, praias, plantações, montanhas, pequenos bairros e grandes cidades, o país produz uma invulgar cultura lúdica que, por meio de um rico artesanato, em conjunto com sua produção industrial, oferece infinitas possibilidades para o brincar. Basta considerar tudo o que a própria natureza e as diferentes culturas locais podem disponibilizar para as brincadeiras com as crianças (Brinquedos e Brincadeiras nas creches, 2012, p. 27).

Ao socializar na prática diária da "Roda da Conversa" algumas "possibilidades para o brincar”, priorizamos as vozes das crianças, como mostram algumas falas das crianças sobre a Dengue:

Eduarda: Dengue é o que faz mal para o seu corpo.

Allysson: Dengue é quando as pessoas ficam doentes.

Lucas: Quando o mosquito da dengue pica a gente, a gente fica com dengue".

Thayla: Sabia que também fica internado quando tem dengue?

Lucas: A minha piscina fica com água parada e o mosquito vem. 
Em acordo com Lipman (1990, p. 32), considero a pedagogia da filosofia ao estabelecer na "roda da conversa", ou em qualquer outro momento, a democracia, ora a partir da escuta atenta aos saberes das crianças, ora a partir da escuta das dúvidas e curiosidades. São momentos nos quais um aprende com o outro e nos quais o diálogo é internalizado por cada um, formando o pensamento.Em outro momento, houve um evento vivenciado por crianças, famílias, educadores, equipe gestora e funcionários, denominado "Brincando em família” (agosto, 2014), em que foram confeccionados brinquedos com sucata e participação em oficinas de Leitura, Massa de Modelar e Jogos, além da exposição dos brinquedos feitos em casa.

Figura 2

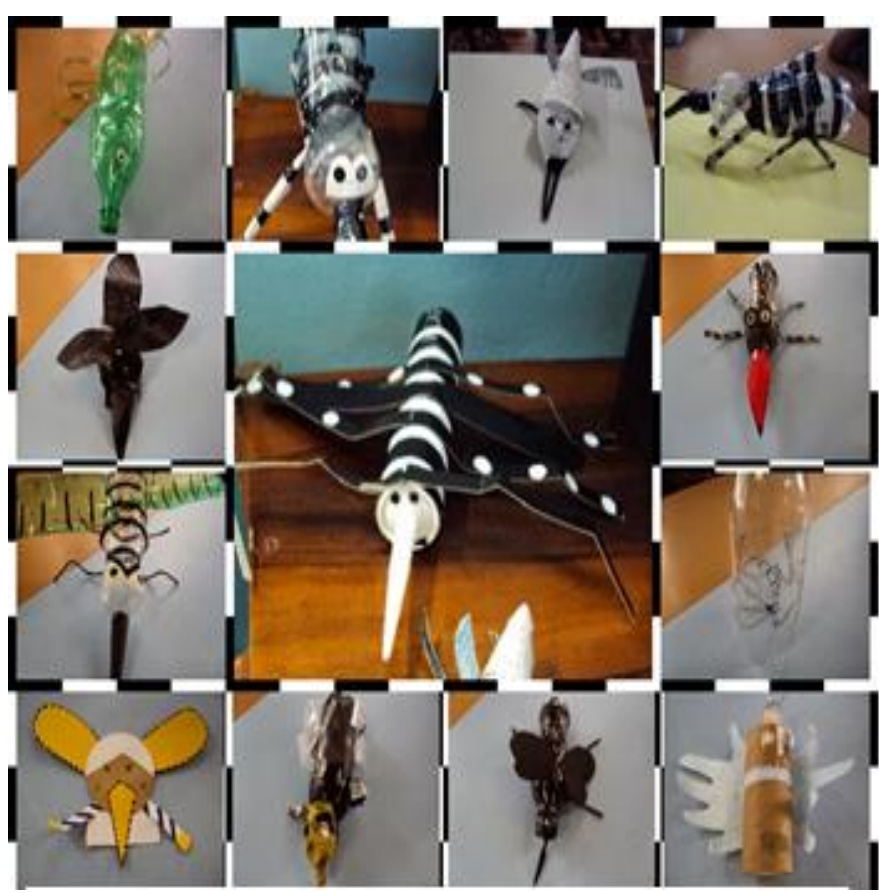

Arquivo da autora. Brinquedos confeccionados pelas crianças.

Uma das crianças da Turma do Jacaré trouxe um pandeiro, que chamou muito a nossa atenção, a família teve o cuidado de utilizar a mesma quantidade de tampinhas para emitir o som desejado do pandeiro, o que pode proporcionar a percepção na produção de diferentes sons, dependendo da quantidade de tampinhas e sua localização na lata.

Figura 3 - Pandero

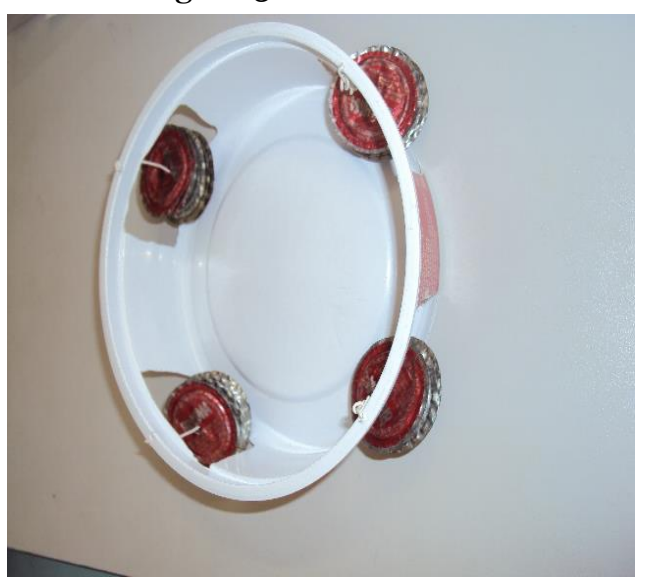


Fonte: Arquivo da autora

A família nos ofereceu o modo de fazer o pandeiro. Vejamos o passo a passo para a sua confecção:

Materiais: 20 tampinhas de garrafa de vidro, 1 pedaço de fio de caderno velho, 1 vasilha de goiabada vazia, 1 alicate de bico, 1 prego, 1 martelo, 1 estilete, 1 faca com bico

$1^{\mathbf{0}}$ Passo: Com o prego fure no centro das tampinhas com o auxílio do martelo. Em seguida abra as laterais e o centro da tampinha batendo com o martelo até ficar completamente aberta. Repita a mesma operação nas demais.

$2^{\mathbf{0}}$ Passo: Pegue a vasilha e com o estilete faça quatro retângulos e, em seguida pegue a faca, aqueça-a no fogo e fure na parte superior e inferior do retângulo, repita nos outros.

$3^{\mathbf{o}}$ Passo: Corte o fio com o alicate, coloque o fio no furo, amarre e coloque cinco tampinhas no arame, depois amarre novamente. Repita esta operação três vezes, em seguida até formar o pandeiro.

Observamos a presença de uma matemática da cultura local na construção desse pandeiro, que podemos chamá-la de Etnomatemática, que é a matemática praticada por grupos culturais como as sociedades indígenas, grupos de trabalhadores como o pedreiro, crianças em suas brincadeiras, enfim de determinadas classes profissionais. Uma matemática que instrumentaliza e tem a ver com a nossa vida.

[...] não é hora de buscarmos uma Matemática que instrumentalize o cidadão para atuar e transformar a realidade em que vive? Uma Matemática crítica, que o ajude a refletir sobre as organizações e relações sociais? Uma Matemática próxima da vida, útil, compreensível, reflexiva? Uma Matemática que não se mostre perfeita, infalível, mas que seja capaz de ajudar a encontrar soluções viáveis? (MUZZI, 2004, P. 39).

\section{Considerações Finais}

O processo pedagógico na Educação Infantil, pensado na perspectiva da Etnomatemática, trouxe possibilidades de percepções do conhecimento matemático associado ao contexto com trânsito entre diversos campos de saberes, impregnados de valores culturais e sociais de forma intensiva, como a própria infância. A postura do professor como parceiro no processo pedagógico que apreende junto com as crianças, torna o conhecimento [...] algo vivo, lidando com situações reais no tempo (agora) e no espaço (aqui) (D’AMBRÓSIO, 2001, p.47), apreendendo dos alunos:

[...] a sua matemática - entendida principalmente como maneira de lidar com relações e comparações quantitativas e com as formas espaciais no mundo real e de fazer classificações e inferências (ibidem, 2001, p.6).

"Maneiras de lidar" na confecção de brinquedos, massa de modelar, pandeiro que possibilitaram interações entre a escola e a família no apreender dos saberes advindos da cultura local e sua consequente valorização. "A cultura popular, embora seja viva e praticada, é muitas vezes ignorada, menosprezada, rejeitada, reprimida e, certamente, diminuída" (D'AMBRÓSIO, 2004, p. 50).

O brincar e o apreender na reutilização de materiais recicláveis possibilitam a criação de seus próprios brinquedos e pode contribuir para afastar as crianças do consumismo desenfreado de brinquedos industrializados. Sabemos que hoje em dia o marketing utiliza o público infantil como isca para vender seus produtos e acumular capital, valendo-se da culpa dos pais por suas ausências 
no cotidiano das crianças, decorrente do modo de vida que, em alguma medida, é exigido nesta contemporaneidade.

Como educadora, preocupo-me em plantar pequenas sementes, no sentido de valorização de pequenas coisas e, do não consumismo, que nem sempre acrescenta na formação das crianças. "Feliz aquele que transfere o que sabe e aprende o que ensina" (Cora Coralina).

\section{Referências}

ABREU, M.L.L.B de. Caminhos da educação infantil em Campinas: o desafio dos agrupamentos ou salas multietárias: Memorial de formação. Faculdade de Educação, Universidade Estadual de Campinas, 2006.

BRASIL. Ministério da Educação. Secretaria de Educação Básica. Brinquedos, brincadeiras $e$ materiais para crianças pequenas: manual de orientação pedagógica: módulo 3 / Ministério da Educação. Secretaria de Educação Básica. - Brasília: MEC/SEB, 2012.

CAMARGO, M. B. de C. Educação Infantil: mapeando vida, espaço, sonhos e desejos expressos no território dos projetos pedagógicos do NAED SUL, Campinas, SP. In DAMIN, M. A. da S. e RIPPER, A. V. A Pesquisa e a Tecnologia na Formação Docente. Campinas: Prefeitura Municipal de Campinas, Secretaria Municipal de Educação, 2013. P. 177 - 191

CAMPINAS. Diretrizes Curriculares da Educação Básica para Educação Infantil: um processo contínuo de reflexão e ação. Campinas, SP: Prefeitura Municipal de Campinas, Secretaria Municipal de Campinas, 2013.

CAMPINAS. Secretaria Municipal de Educação. Resolução n ${ }^{0}$ 23/2002, publicada em Diário Oficial do dia 13/11/2002

COSTA, E. A. P. da. O primeiro leitor e a formação das profissionais da Educação Infantil. In FARIA, Ana Lúcia Goulart de; MELLO, Suely Amaral, organizadoras. Territórios da infância: linguagens, tempos e relações para uma pedagogia para as crianças pequenas. Araraquara, SP: Junqueira \& Marin, 2007.

D’AMBROSIO, U. Uma História Concisa da Matemática no Brasil. Petrópolis, RJ: Vozes, 2008. . Etnomatemática e educação. In: KNIJNIK, Gelsa; WANDERER, Fernanda; OLIVEIRA, Cláudio José de. Etnomatemática: currículo e formação de professores. Santa Cruz do Sul, RG: EDUNISC, 2004.

. Etnomatemática: elo entre a tradição e a modernidade. Belo Horizonte: Autêntica, 2001.

KOHAN, W. A infância da educação: o conceito devir-criança. In: Kohan,Walter (org). Lugares da infância: Filosofia. Rio de Janeiro: DP\&A, 2004.

LIPMAN, M. A filosofia vai à escola. São Paulo: Summus, 1990.

MALAGUZZI, L. As Cem Linguagens da Criança. Porto. Alegre: Artes Médicas, 1997.

MUZZI, M. Etnomatemática, Modelagem e Matemática Crítica: novos caminhos. In: Presença Pedagógica, v. 10, $\mathrm{n}^{0}$ 56, mar./abr. 2004. p. 31-39.

OLIVEIRA, E. D, de. Filosofia da Ancestralidade: Corpo de Mito na Filosofia da Educação Brasileira. Curitiba, Gráfica Popular, 2007.

PRADO, P. D. Contrariando a idade: condição infantil e relações etárias entre crianças pequenas da Educação Infantil. 2006. Doutorado. Faculdade de Educação, Universidade Estadual de Campinas, Campinas, 2006.

\section{Biografia Resumida}

Érica Helena de Proença Alexandrini. Licenciada em Pedagogia pela

Faculdade de Educação da Universidade Estadual de Campinas, 2005. Especialista em "Linguagem, Práticas Discursivas e Criança", pela Faculdade de Educação da Universidade Estadual de Campinas, 2011. Professora de Educação Infantil da Prefeitura Municipal de Campinas, no Centro de Educação Infantil “João Vialta”, desde o8/o8/200o, no 
Com a Palavra o Professor, Vitória da Conquista (BA), v. 2, n.3, maio - agosto/ 2017

agrupamento III-D, que possuem faixas etárias entre três anos e meio a seis anos.

Contato: ericaalexandrini@gmail.com 